\title{
COX-2 overexpression in resected pancreatic head adenocarcinomas correlates with favourable prognosis
}

\author{
Ewa Pomianowska ${ }^{1,2^{*}}$, Aasa R Schjølberg ${ }^{1,3}$, Ole Petter F Clausen ${ }^{3}$ and Ivar P Gladhaug ${ }^{1,2}$
}

\begin{abstract}
Background: Overexpression of cyclooxygenase-2 (COX-2) has been implicated in oncogenesis and progression of adenocarcinomas of the pancreatic head. The data on the prognostic importance of COX expression in these tumours is inconsistent and conflicting. We evaluated how COX-2 overexpression affected overall postoperative survival in pancreatic head adenocarcinomas.

Methods: The study included 230 consecutive pancreatoduodenectomies for pancreatic cancer ( $P C, n=92)$, ampullary cancer ( $A C, n=62)$ and distal bile duct cancer ( $D B C, n=76)$. COX-2 expression was assessed by immunohistochemistry. Associations between COX-2 expression and histopathologic variables including degree of differentiation, histopathologic type of differentiation (pancreatobiliary vs. intestinal) and lymph node ratio (LNR) were evaluated. Unadjusted and adjusted survival analysis was performed.
\end{abstract}

Results: COX-2 staining was positive in $71 \%$ of $P C, 77 \%$ in $A C$ and $72 \%$ in DBC. Irrespective of tumour origin, overall patient survival was more favourable in patients with COX-2 positive tumours than COX-2 negative $(p=0.043$ in $P C, p=0.011$ in $A C, p=0.06$ in DBC). In tumours of pancreatobiliary type of histopathological differentiation, COX-2 expression did not significantly affect overall patient survival. In AC with intestinal differentiation COX-2 expression significantly predicted favourable survival $(p=0.003)$. In $P C$, COX-2 expression was significantly associated with high degree of differentiation $(p=0.002)$. COX-2 and LNR independently predicted good prognosis in a multivariate model.

Conclusions: COX-2 is overexpressed in pancreatic cancer, ampullary cancer and distal bile duct cancer and confers a survival benefit in all three cancer types. In pancreatic cancer, COX-2 overexpression is significantly associated with the degree of differentiation and independently predicts a favourable prognosis.

\section{Background}

Primary adenocarcinomas located in the pancreatic head arise from the ampulla, the distal bile duct, or the pancreatic ductal structures. Due to the topological proximity of these structures, resectable adenocarcinomas arising from any of these three anatomical locations are typically resected by the same surgical procedure, i.e. curativeintent pancreatoduodenectomy. The considerable variation in reported frequencies for the individual tumour

\footnotetext{
* Correspondence: ewa.pomianowska@medisin.uio.no

'Institute of Clinical Medicine, Faculty of Medicine, University of Oslo, Oslo, Norway

${ }^{2}$ Department of Hepato-pancreato-biliary Surgery, Oslo University Hospital, Rikshospitalet, PO Box 4950, Nydalen, 0424 Oslo, Norway

Full list of author information is available at the end of the article
}

sites suggests that the precise tumour origin may be difficult to determine [1] and that the applied methods for histopathological determination of the cancer origin varies widely among institutions [2]. Adenocarcinomas from all three locations may be of pancreatobiliary or intestinal type of differentiation [3].

Overexpression of cyclooxygenase-2 (COX-2) has been described in several tumours, including colon, stomach, breast, lung, and urinary bladder [4-16]. The COX-2 expression is a component of the cellular response to inflammation and is induced by several extracellular or intracellular stimuli, including proinflammatory cytokines, infectious agents, mitogens, hormones and growth factors $[17,18]$. Several studies have reported overexpression of COX-2 in subsets of pancreatic adenocarcinomas 
in $37-80 \%$ of the tumours investigated [19-26]. Increased COX-2 expression has also been demonstrated in pancreatic intraepithelial neoplasias (PanINs) [27-30]. However there is relatively few data on COX-2 expression in the two other types of pancreatic head adenocarcinomas, ampullary cancer [31-33] and distal bile duct cancer [34]. Data on prognostic relevance of COX-2 overexpression in all these tumours has been inconsistent and conflicting although most reports indicate an inverse relationship between COX-2 overexpression and survival rates in pancreatic cancer $[19,21]$ and ampullary cancer [32].

The aim of the present study was to examine the prognostic relevance of COX-2 expression in adenocarcinomas from the three separate anatomical sites of origin in the pancreatic head. The data shows that COX-2 is overexpressed in all three types of pancreatic head adenocarcinomas and that COX-2 overexpression is associated with better survival. In contrast to previous reports, COX-2 overexpression was found to be an independent prognostic factor for better survival in pancreatic adenocarcinoma.

\section{Methods}

Patients

The study included 230 consecutive patients (103 women and 127 men) undergoing a standard Whipple's procedure for adenocarcinoma with curative intent 1998 -2011 at Oslo University Hospital, Rikshospitalet. The study was approved by the Regional Committee for Medical and Health Research Ethical for Southern Norway.

Standard demographic, clinicopathological, and tumourspecific data were collected retrospectively from hospital records. Overall survival data was obtained from the Norwegian Population Registry, updated June 20, 2013. Since all Norwegian inhabitants receive a unique personal identification number, no patients were lost to follow-up in the present study. Patients were followed until death or censored after maximum five years (60 months). By the end of the study 177 patients were dead. Median follow-up for the remaining 53 patients was 62 months (interquartile range $29-119$ months). Perioperative death (defined as death within 30 days of operation) was included in the analyses (four patients). Analysis excluding perioperative death gave similar results. None of the patients received preoperative chemotherapy or chemoradiotherapy. From 2008, adjuvant chemotherapy with 5-fluororuracil was recommended for eligible patients operated for pancreatic cancer. Thirty-nine percent of the patients (13 of 33) operated in this period received adjuvant chemotherapy (5-FU-based in 11 patients, 2 patients received gemcitabine).

\section{Histopathological evaluation of resection specimens}

The resection specimens were examined according to a standardized protocol as described previously [1,35]. All registered parameters of the prospectively collected data base, including anatomic site of tumour origin, where later reevaluated by slide review [1]. The histological type of differentiation was evaluated and all tumours were classified either as intestinal or pancreatobiliary type $[3,36]$. In brief, pancreatobiliary tumours typically have simple or branching glands and small solid nests of cells surrounded by a desmoplastic stroma, and have cuboideal to low columnar epithelium arranged in a single layer and the nuclei are rounded but with marked variation in size and shape from one cell to the next. Intestinal tumours typically resembled colon cancer, have tall and often pseudostratified columnar epithelium with oval nuclei located in the more basal aspect of the cytoplasm, and there may also often be presence of mucin [36,37].

\section{Immunohistochemistry}

Formalin-fixed, paraffin-embedded tissue was sectioned $(3 \mu \mathrm{m})$, dried at $60^{\circ} \mathrm{C}$, and processed in a Ventana BenchMark Ultra machine (Ventana Medical Systems Inc. (Tucson Arizona USA). Slides were incubated with monoclonal anti-COX-2 antibodies (Thermo Fischer Scientific rabbit), Universal Alkaline Phosphatase Red Detection Kit (Ultra View 760-501) and $\alpha$ SMA (Dako M.0851), DAB (Ultra View 760-500). Additional immunostaining on duplicates of twenty slides was performed with monoclonal COX-2 mouse antibody Invitrogen (Camarillo, CA, USA). Slides were counterstained with haematoxylin, fixed, mounted and analyzed using an inverted light microscope (Olympus, Center Valley, PA, USA).

\section{Evaluation of COX-2 immunostaining}

Immunohistochemistry was performed on whole tumour slices, which were assessed without prior knowledge of the clinical and pathological parameters. In each section, five different representative high-power fields $(100 \times)$ with tumour infiltration were selected and examined by light microscopy. The intensity of staining was estimated on a scale from 1-3 (1-negative, 2-moderate, 3-strong). Cells were considered positive only if COX-2 intensity was moderate or strong. The extent of the immunolabeling was assessed as the percentage of positively stained tumour cells and was expressed on the scale from 1-3 where 1 represented less than 10\% cells stained, 2 represented $10-50 \%$ and 3 over 50\%. Since COX-2 demonstrated considerable heterogeneity within individual cases, the final immunoscore was obtained as the average of the numeric scores for five high-power fields of each case considered positive in intensity scoring. Based on histograms of the staining for all tumours, the optimal cut-off value for discrimination between negative and positive staining was found to be 1.4. Islets of Langerhans and mucosa of the duodenum were moderately to 
strongly positive for COX-2, including those tumours with no COX-2 expression, and served as internal controls. Identical sections with omission of the primary antibody were used as negative controls. To test the validity of the Thermo antibody used for the study cohort, we performed additional immunostaining with a different monoclonal COX-2 mouse antibody, Invitrogen (Camarillo, CA, USA), on duplicates of twenty pancreatic cancer slides from the study cohort. The results were identical (Figure 1a and e). As Thermo antibody was not suitable for western blotting (producer recommendation), only the Invitrogen antibody was subjected to analysis by western blotting. The results showed a highly specific bond for COX-2 (Figure 1f).

Almost half of study specimens (44\%) were evaluated independently by two examiners (EP and AS) and kappa interobserver was 0.73, indicating substantial agreement (95\% CI 0.6-0.9).

\section{Statistical analysis}

Associations between variables were examined using Chi-square test, Fisher's exact test and Mann-Whitney test. Continuous variables were reported as median with corresponding range or interquartile range (IQR). Unadjusted survival analysis was performed using the Kaplan-Meier method, comparing curves using log-rank test. Multivariable Cox regression analysis was used for adjusted survival analysis. Possible interactions were evaluated by inclusion of an interaction term in the models. For all tests, a two-sided $\mathrm{p}<0.05$ was considered statistically significant. Statistical analyses were performed in SPSS 19 for Windows (SPSS Inc., Chicago, IL).

\section{Results}

The study cohort consisted of 230 patients consecutively resected for adenocarcinomas originating from the ampulla $(A C)(n=62,27 \%)$, distal bile duct (DBC) $(n=76$, $33 \%)$, or pancreas $(\mathrm{PC})(\mathrm{n}=92,40 \%)$. Median age at time of resection was similar for the three groups (67 years, range $37-83 ; \mathrm{p}=0.463$ Kruskal-Wallis). Overall 5-year (actual) survival was $5 \%$ for PC, $16 \%$ for DBC, and $44 \%$ for $\mathrm{AC}(\mathrm{p}<0.001)$.

\section{COX-2 expression and prognosis in ampullary, distal bile duct and pancreatic cancer}

COX-2 staining was very similar in all three tumour types, with a positivity rate of $71 \%$ in $\mathrm{PC}, 72 \%$ in $\mathrm{DBC}$, and $77 \%$ in $\mathrm{AC}$. The COX-2 expression was detected in the cytoplasm of cancer cells in all three types of adenocarcinoma. No COX-2 immunostaining was detected in the stroma cells (Figure 1a,b, and e). The expression pattern showed heterogeneity both among different tumours and within the individual tumour, as areas with moderate to strong staining coexisted with negative areas within the same tumour (Figure 1c). Islet cells expressed moderately to strong COX-2 staining in all cases including those with no COX-2 expression in the tumour (Figure 1d). Irrespective of tumour origin, overall patient survival was more favourable in COX-2 positive than COX-2 negative tumours (Figure 2a-c). This was particularly prominent in $\mathrm{AC}(\mathrm{p}=0.011)$ and $\mathrm{PC}(\mathrm{p}=0.043)$ whereas the same tendency was seen in $\mathrm{DBC}$ although not reaching significance $(\mathrm{p}=0.06)$. COX-2 expression varied according to the type of histological differentiation. In tumours with pancreatobiliary type of differentiation, two thirds of the tumours were $\mathrm{COX}-2$ positive irrespective of anatomical origin $(67 \%, 69 \%$, and $68 \%$ in AC, $\mathrm{DBC}$ and $\mathrm{PC}$, respectively). However there was no significant difference in overall survival when comparing COX-2 positive and negative tumours in this group (Figure 2d-f). All PC and DBC tumours with intestinal type of differentiation were COX-2 positive whereas $84 \%$ of the intestinal AC tumours expressed COX-2. The survival data of the intestinal AC tumours showed a favourable prognosis for patients with tumours expressing COX-2 ( $\mathrm{p}=0.003)$ (Figure 2g-i).

\section{Factors associated with prognosis in pancreatic adenocarcinoma}

COX-2 expression status was compared across clinical parameters associated with survival in the subgroup consisting of the 92 patients resected for pancreatic adenocarcinoma. The median survival for patients with COX-2 positive tumours was 18 months (95\% CI 14-22) as compared to 11 months (95\% CI 9.6-12) for patients with COX-2 negative tumours $(\mathrm{p}=0.043)$. COX-2 positive tumours were more likely associated with high degree of differentiation $(\mathrm{p}=0.002)$ and with intestinal type of differentiation, although, the latter did not reach significance $(\mathrm{p}=0.099)$ (Table 1$)$ probably due to the low number of tumours of the intestinal differentiation type.

There was no association with COX-2 positivity and R-status, lymph node ratio (LNR), lymph node status, tumour diameter, $\mathrm{T}$ classification, and vascular or perineural infiltration (Table 1). Since tumours expressing COX-2 were significantly more likely to be highly differentiated than COX-2 negative tumours, the joint effects of COX-2 status and differentiation grade on survival were assessed by Kaplan-Meier analysis, stratifying for COX-2 status (positive vs. negative) and differentiation grade (grade 1 and 2 vs. grade 3 and 4) (Figure 3a). Patients whose tumours did not express COX-2 and had a low differentiation grade (grade 3 and 4) had significantly poorer survival than the other three groups $(\mathrm{p}=0.006)$.

In a previous report we found that LNR independently predicted prognosis in a multivariate model for survival 


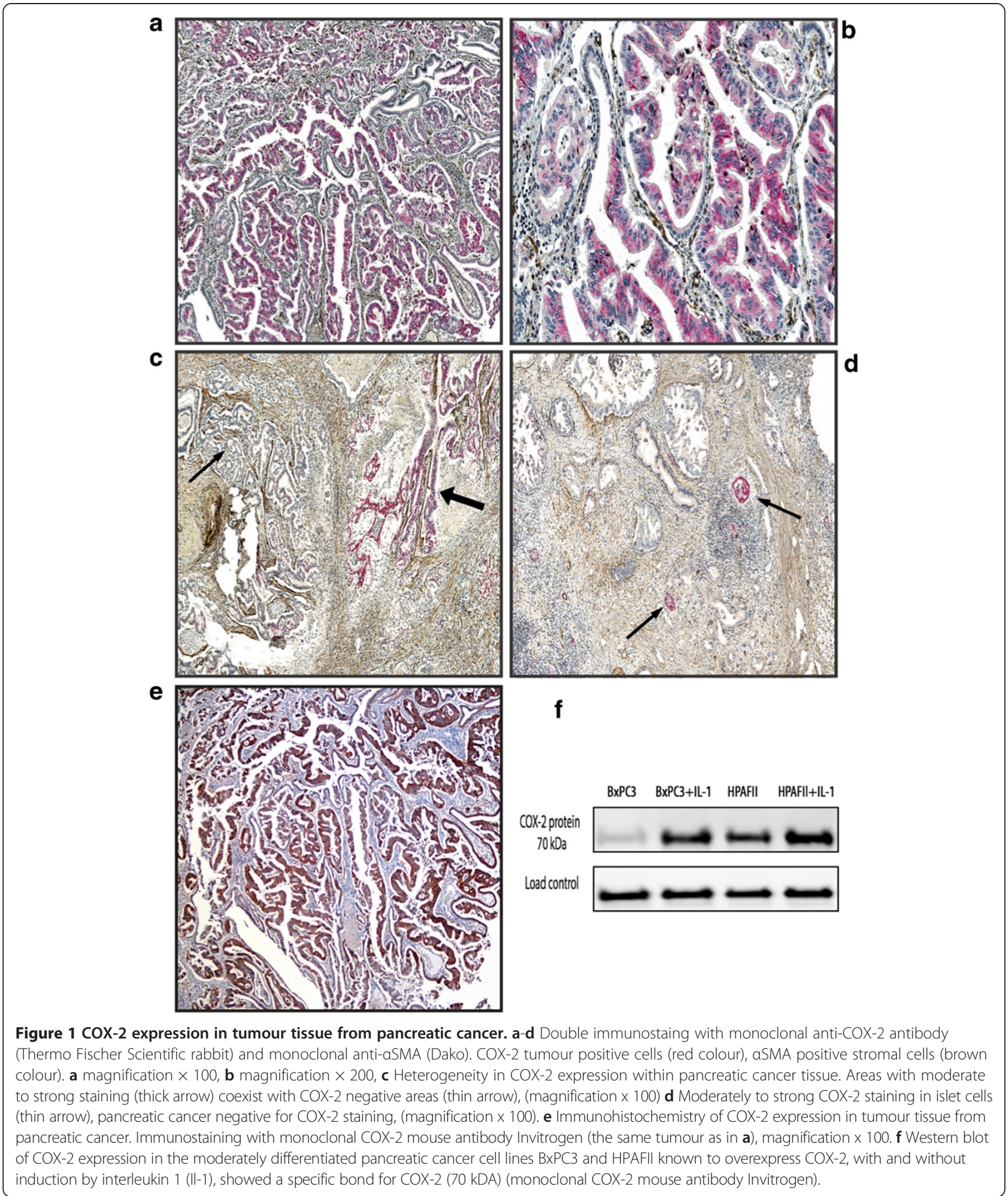

in resected pancreatic cancer [38]. We thus also examined the joint effects of COX-2 status and LNR, and found that patients with COX-2 negative tumours and LNR $>0.2$ had significantly worst prognosis $(\mathrm{p}<0.001)$ (Figure $3 \mathrm{~b})$.
In a multivariate analysis model including COX-2 expression, LNR, tumour size, margin status, vascular and perineural infiltration, COX-2 negative tumours and LNR $>0.2$ independently predicted poor prognosis 


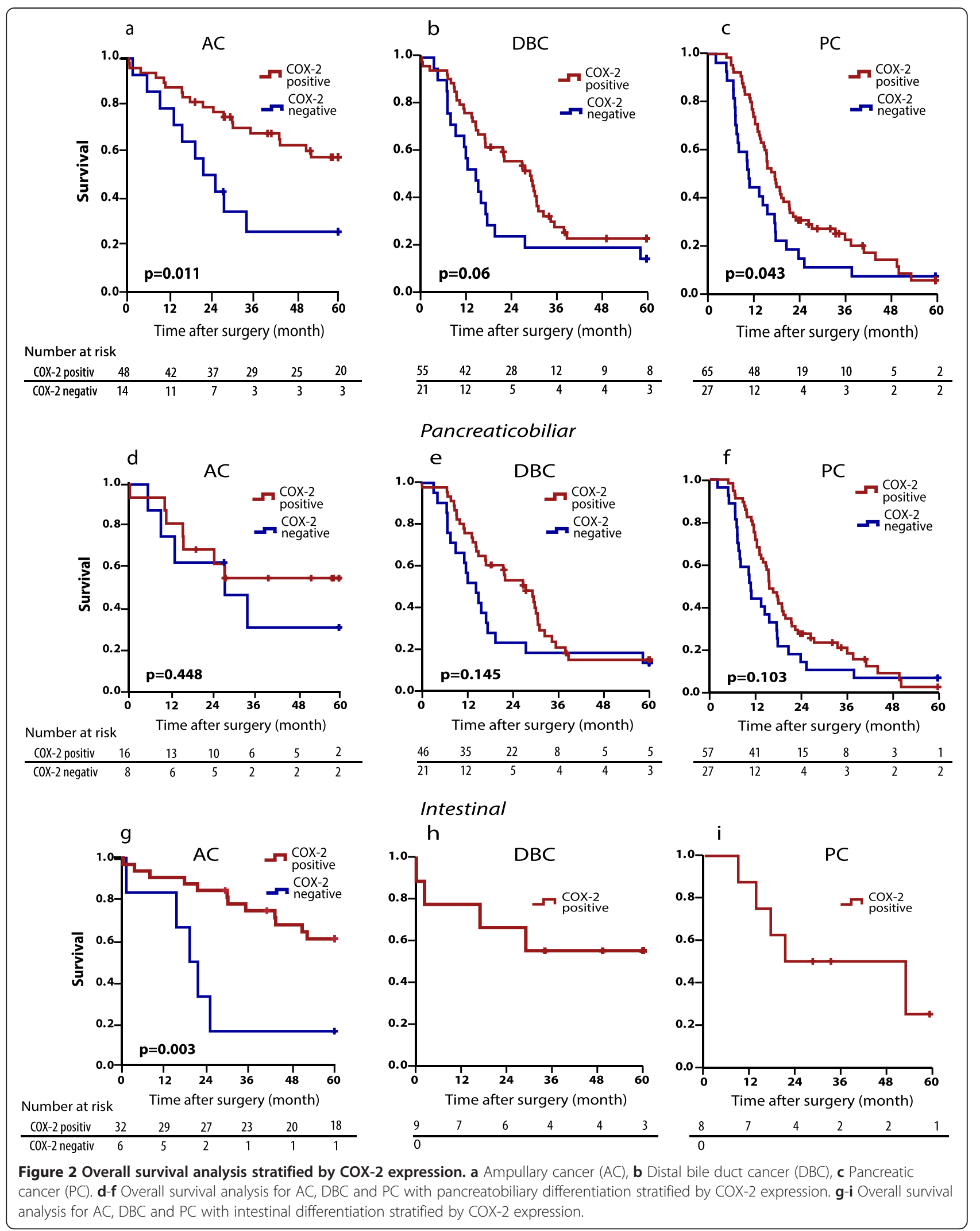


Table 1 Clinicopathological variables in 92 consecutive pancreatoduodenectomies for pancreatic cancer stratified by COX-2 status

\begin{tabular}{|c|c|c|c|c|}
\hline Characteristic & $n(\%)$ & COX2-neg. n(\%) & COX2-pos. n(\%) & $p^{a}$ \\
\hline \multicolumn{5}{|l|}{$\overline{C O X}-2$} \\
\hline Positive & $65(71 \%)$ & & & \\
\hline Negative & 27 (29\%) & & & \\
\hline \multicolumn{5}{|l|}{ Tumour size } \\
\hline$\leq 20 \mathrm{~mm}$ & $15(16 \%)$ & $3(20 \%)$ & $12(80 \%)$ & \\
\hline$>20 \mathrm{~mm}$ & $77(84 \%)$ & $24(31 \%)$ & $53(69 \%)$ & $0.54^{\mathrm{b}}$ \\
\hline \multicolumn{5}{|l|}{ Lymph node metastasis } \\
\hline No, n (\%) & $25(27 \%)$ & $5(20 \%)$ & $20(80 \%)$ & \\
\hline N1, n (\%) & $67(73 \%)$ & $22(33 \%)$ & $45(67 \%)$ & 0.229 \\
\hline \multicolumn{5}{|l|}{ Lymph node ratio $(\mathrm{LNR})^{\mathrm{C}}$} \\
\hline$\leq 0.2$ & $54(59 \%)$ & $13(24 \%)$ & $41(76 \%)$ & \\
\hline$>0.2$ & $37(41 \%)$ & $13(36 \%)$ & $24(65 \%)$ & 0.251 \\
\hline \multicolumn{5}{|l|}{ Vascular invasion } \\
\hline No, n (\%) & 30 (33\%) & $12(40 \%)$ & 18(60\%) & \\
\hline Yes, n (\%) & $62(67 \%)$ & $15(24 \%)$ & $47(76 \%)$ & 0.119 \\
\hline \multicolumn{5}{|l|}{ Perineural infiltration } \\
\hline No, n (\%) & $15(16 \%)$ & $3(20 \%)$ & $12(80 \%)$ & \\
\hline Yes, n (\%) & 77 (84\%) & $24(31 \%)$ & $53(69 \%)$ & $0.54^{\mathrm{b}}$ \\
\hline \multicolumn{5}{|l|}{ T classification } \\
\hline $\mathrm{T} 1$ & $3(3 \%)$ & $1(33 \%)$ & $2(67 \%)$ & \\
\hline $\mathrm{T} 2$ & $6(7 \%)$ & $1(17 \%)$ & $5(83 \%)$ & \\
\hline $\mathrm{T} 3$ & $83(90 \%)$ & $25(30 \%)$ & $58(70 \%)$ & $0.851^{\mathrm{b}}$ \\
\hline \multicolumn{5}{|l|}{$\mathrm{R} 1$ resection status, $\mathrm{n}(\%)$} \\
\hline Ro, n (\%) & $40(44 \%)$ & $10(25 \%)$ & $30(75 \%)$ & \\
\hline R1, n (\%) & $52(56 \%)$ & $17(33 \%)$ & $35(67 \%)$ & 0.422 \\
\hline \multicolumn{5}{|l|}{ Degree of differentiation } \\
\hline Grade I, II & $53(58 \%)$ & $9(17 \%)$ & $44(83 \%)$ & \\
\hline Grade III, IV & $39(42 \%)$ & $18(46 \%)$ & $21(54 \%)$ & 0.002 \\
\hline \multicolumn{5}{|l|}{ Type of differentiation } \\
\hline Pancreaticobiliary, n (\%) & $84(91 \%)$ & $27(32 \%)$ & $57(68 \%)$ & \\
\hline Intestinal, n (\%) & $8(9 \%)$ & $0(0 \%)$ & $8(100 \%)$ & $0.099^{b}$ \\
\hline
\end{tabular}

PC, pancreatic adenocarcinoma.

${ }^{\mathrm{a}}$ Chi-square test, when not otherwise specified.

${ }^{\mathrm{b}}$ Fisher's Exact Test.

'LNR assessment of 91 patients since in one specimen no lymph nodes were retrieved.

(Table 2). Since there was a strong correlation between COX-2 expression and differentiation grade $(\mathrm{p}=0.002)$ it was not possible to include differentiation grade in the same model.

Only a minority of the patients received adjuvant chemotherapy. Although the numbers are small, there was no difference in survival between patients with COX-2 positive and COX-2 negative tumours who received adjuvant treatment.

\section{Discussion}

There is a large body of epidemiological, clinical and molecular evidence suggesting that COX-2 is implicated in the oncogenesis and progression of gastrointestinal malignancies, including adenocarcinomas derived from pancreatic head structures. It has previously been shown that COX-2 is upregulated in subsets of pancreatic, ampullary and distal bile duct adenocarcinomas although the proportion of upregulated tumours varies in the 


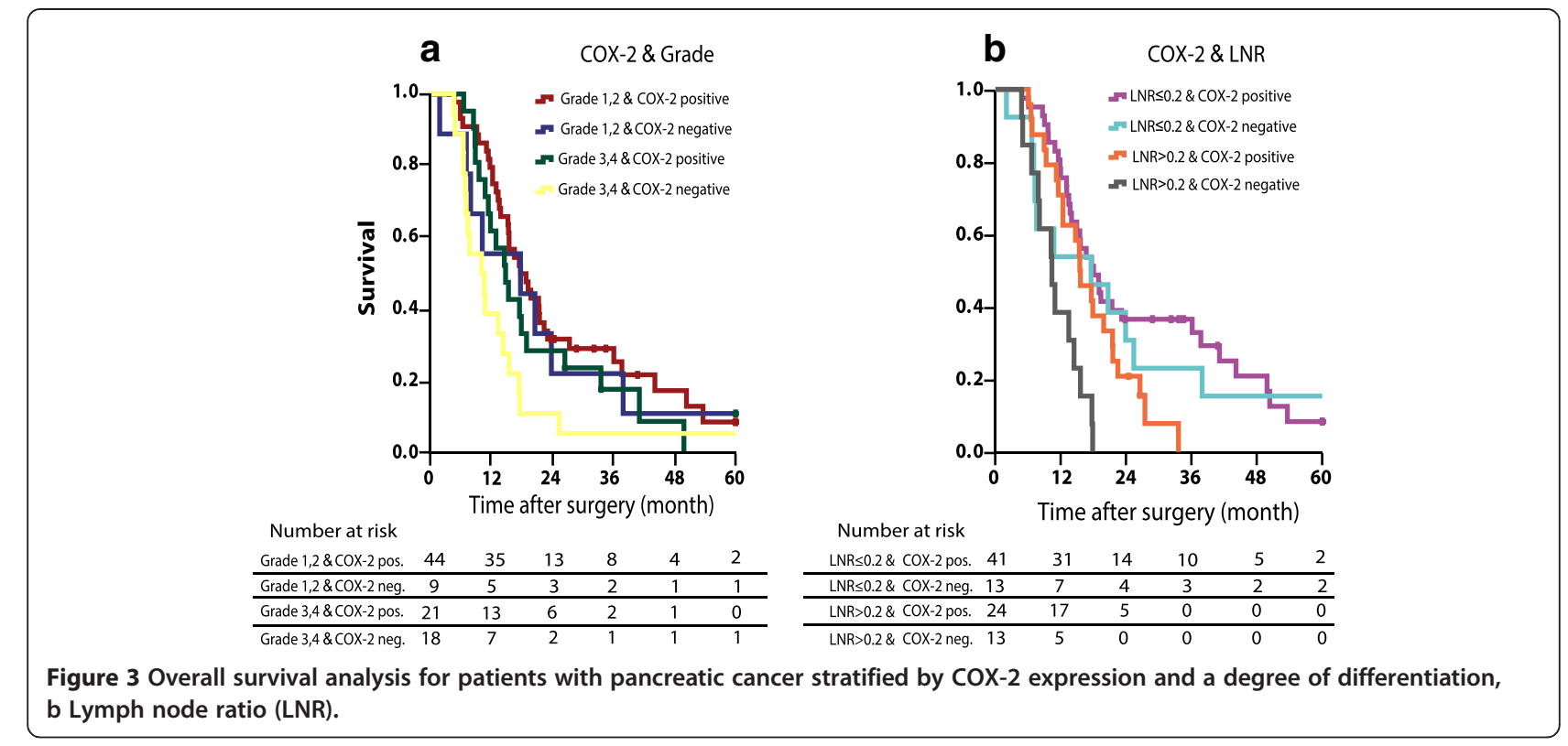

different reports. Furthermore, data on the prognostic importance of COX-2 expression in these tumours is conflicting. In pancreatic adenocarcinoma, two studies reported that COX-2 expressing tumours were associated with worse overall prognosis $[19,21]$ whereas other studies have suggested a trend towards better prognosis for tumours with high COX-2 expression [22] or no association at all [39-41]. The present data on pancreatic, distal bile duct and ampullary adenocarcinomas indicates a more favourable overall survival for patients with COX-2 expressing tumours.

In periampullary and pancreatic head tumours, we have previously shown that histologic subtyping of these tumours into intestinal and pancreatobiliary types correlates with cell-type specific markers [36] and prognosis $[3,37]$. As COX-2 is thought to be expressed in epithelial cells throughout the gastrointestinal tract $[5,12,42]$ it

Table 2 Multivariate Cox regression analysis of histopathologic factors in $\mathbf{9 2}$ patients with pancreatic cancer

\begin{tabular}{|c|c|c|c|}
\hline & $p$-value & HR & $95 \% \mathrm{Cl}$ \\
\hline R-status (R1vs R0) & 0.87 & 1.038 & $0.65-1.65$ \\
\hline $\begin{array}{c}\text { Vascular invasion } \\
\text { (Involved vs non- involved) }\end{array}$ & 0.455 & 1.208 & $0.74-1.98$ \\
\hline $\begin{array}{l}\text { Perineural infiltration } \\
\text { (Involved vs non- involved) }\end{array}$ & 0.359 & 1.369 & $0.70-2.68$ \\
\hline $\begin{array}{c}\text { Tumour size } \\
(>20 \mathrm{~mm} \text { vs } \leq 20 \mathrm{~mm})\end{array}$ & 0.315 & 1.434 & $0.71-2.90$ \\
\hline $\begin{array}{l}\text { COX-2 expression } \\
\text { (Negative vs Positive) }\end{array}$ & 0.047 & 1.642 & $1.01-2.68$ \\
\hline $\begin{array}{l}\text { Lymph node ratio } \\
(\text { LNR })(>0.2 \text { vs } \leq 0.2)\end{array}$ & 0.032 & 1.757 & $1.05-2.94$ \\
\hline
\end{tabular}

was of particular interest to examine whether there are differences in COX-2 expression in the intestinal and pancreatobiliary subtypes. Of note, most intestinal ampullary tumours (84\%) were COX-2 positive, and in particular, all intestinal pancreatic and distal bile duct tumours were COX-2 positive. Patients with ampullary cancers of the intestinal subtype, which expressed COX-2, had a favourable prognosis with a 5-year actual survival of $60 \%$. Histopathologic type of differentiation combined with biomarkers or gene expression profiles has recently attracted interest as important factors for outcome as well as stratification for adjuvant chemotherapy in ampullary adenocarcinoma $[43,44]$.

The finding in the present study that COX-2 expression correlates with a favourable prognosis in pancreatic cancer can be explained by the fact that there is a statistically significant association between COX-2 positivity and high degree of differentiation. More than $80 \%$ of tumours with high differentiation grade showed overexpression of COX-2. This result is consistent with previous observations from studies of cultured pancreatic cancer cells and pancreatic cancer tissue. In cultured tumour cells COX-2 expression was found to be restricted to moderately and highly differentiated pancreatic cancer cell lines $[23,26,45]$. In human pancreatic adenocarcinoma tissue, well differentiated lesions expressed COX-2 to the highest degree, whereas there was less expression of COX-2 in moderately and poorly differentiated lesions [30]. In our study, the subgroup of patients with COX-2 positive/well differentiated tumours had a significantly better survival compared to patients with COX-2 negative/poorly differentiated tumours, whereas COX-2 positive/poor differentiation and COX-2 negative/high differentiation formed 
an intermediate group with respect to survival. Thus the presence of COX-2 expression in these tumours appears to be a marker of favourable prognosis closely linked to the degree of tumour differentiation. Consistent with the latter the strong statistical association between COX-2 expression and differentiation grade precluded inclusion of both variables in the same multivariable model for survival.

The precise function of COX-2 in pancreatic cancer development is not known. In the normal pancreas, only islet cells always express COX-2 [24]. In transgenic mice models, overexpression of COX-2 in normal pancreatic ductal cells results in development of dysplastic changes resembling IPMNs and PanINs [46,47] suggesting a primary role of pancreatic cell COX-2 overexpression in the initiation of ductal adenocarcinoma. Recent evidence suggests that this is an intrinsic role of pancreatic cells independent of prostaglandins from the tumour microenvironment [48]. These observations support the concept that COX-2 overexpression might be a causal factor in pancreatic cancer development. It has also been suggested that pancreatic cancers that lack COX-2 (and COX-1) depends on exogenic prostaglandins from stromal fibroblasts for proliferation and other cancer-promoting effects [49]. Since COX-2 overexpression is implicated in tumour development, its expression in pancreatic cancer was hypothesized to result in a poor patient prognosis [19]. This hypothesis is difficult to reconcile with the observation that in fully developed tumours, COX-2 expression has been shown to be a function of differentiation status, with highest expression in well differentiated tumours [30]. In addition, it has been demonstrated that COX-2 expression varies markedly throughout the pathological process of pancreatic neoplasia. COX-2 expression increases in a stepwise manner with each initial stage of neoplastic progression up to the PanIN 2 stage, whereas COX-2 expression was relatively lower in invasive cancers [30].

Some of the discrepancies in results between our study and the studies by Juuti et al [19] and Matsubayashi et al [21] might be explained by methodological differences in patient sampling and/or tumour immunohistochemistry techniques. Since it is well known that it can be difficult to determine the precise anatomical origin of tumours of the pancreatic head, all cancers in the present series were re-evaluated for correct sub-classification into ampullary, distal bile duct or pancreatic tumours. There are also certain differences pertaining to the immunohistochemistry protocols that differ in our study compared to the studies by Juuti et al [19] and Matsubayashi et al [21]. In the work of Juuti, more than 30 years old specimens were included in the study cohort. It is known that for immunohistochemical staining protocols aging of fixed tumour tissue might interfere with staining [50].
Not only aging of the waxed specimen itself, but also variations in fixation protocols over time may result in inadequate staining. This may partly explain the low frequency of COX-2 staining (36\%) in their data, compared to $55-80 \%$ in most other reports $[20,22,23,25,26,41,51]$. Since COX-2 expression in pancreatic tumours often is heterogeneous $[24,29,30]$, the actual number of COX-2 positive tumours might be underestimated unless immunohistochemistry is performed on whole slide sections and assessed on multiple different high-power fields within each tumour. In the study of Matsubayashi [21], assessment of COX-2 staining was performed on tissue microarrays. Although this method has many advantages, tissue microarrays might not be the optimal method for assessment of COX-2 staining even if two cores of tumour tissues were studied from each tumour. This may partly explain the lower proportion of tumours expressing COX-2 in some studies $[19,21]$ and hence the differences in patient survival.

\section{Conclusion}

COX-2 is overexpressed in pancreatic cancer, ampullary cancer and distal bile duct cancer and confers a survival benefit in all three cancer types. The overexpression is consistently linked to the histopathological type of differentiation and to the degree of differentiation. In pancreatic adenocarcinoma, COX-2 overexpression independently predicts a favourable prognosis.

\section{Competing interests}

The authors declare that they have no competing interests.

\section{Authors' contributions}

EP, OPC, IPG conceived and planned the study. EP and IPG conducted acquisition of data. EP, ARS, and OPC performed immunohistochemistry. EP, ARS, OPC and IPG analysed and discussed the results. EP and IPG drafted the manuscript. All authors critically revised and approved of the final manuscript.

\section{Acknowledgements}

The authors gratefully acknowledge Maria Einarsen Pretorius for technical assistance with scanning of slides, and Knut Jørgan Labori for supplying unpublished data on adjuvant chemotherapy. We thank Dagny Sandnes, Vegard Tjomsland and Arne Westgaard for helpful discussions.

\section{Author details}

${ }^{1}$ Institute of Clinical Medicine, Faculty of Medicine, University of Oslo, Oslo, Norway. ${ }^{2}$ Department of Hepato-pancreato-biliary Surgery, Oslo University Hospital, Rikshospitalet, PO Box 4950, Nydalen, 0424 Oslo, Norway.

${ }^{3}$ Department of Pathology, Oslo University Hospital, Rikshospitalet, Oslo, Norway.

Received: 3 October 2013 Accepted: 11 June 2014 Published: 20 June 2014

\section{References}

1. Pomianowska E, Grzyb K, Westgaard A, Clausen OP, Gladhaug IP: Reclassification of tumour origin in resected periampullary adenocarcinomas reveals underestimation of distal bile duct cancer. Eur J Surg Oncol 2012, 38:1043-1050.

2. Verbeke CS, Gladhaug IP: Resection margin involvement and tumour origin in pancreatic head cancer. Br J Surg 2012, 99:1036-1049. 
3. Westgaard A, Pomianowska E, Clausen OP, Gladhaug IP: Intestinal-type and pancreatobiliary-type adenocarcinomas: how does ampullary carcinoma differ from other periampullary malignancies? Ann Surg Oncol 2013, 20:430-439.

4. Kawai N, Tsujii M, Tsuji S: Cyclooxygenases and colon cancer. Prostaglandins Other Lipid Mediat 2002, 68-69:187-196.

5. Sano H, Kawahito Y, Wilder RL, Hashiramoto A, Mukai S, Asai K, Kimura S, Kato $\mathrm{H}$, Kondo M, Hla T: Expression of cyclooxygenase-1 and -2 in human colorectal cancer. Cancer Res 1995, 55:3785-3789.

6. Saukkonen K, Nieminen O, Van RB, Vilkki S, Harkonen M, Juhola M, Mecklin JP, Sipponen P, Ristimaki A: Expression of cyclooxygenase-2 in dysplasia of the stomach and in intestinal-type gastric adenocarcinoma. Clin Cancer Res 2001, 7:1923-1931.

7. Ristimaki A, Sivula A, Lundin J, Lundin M, Salminen T, Haglund C, Joensuu $H$ Isola J: Prognostic significance of elevated cyclooxygenase-2 expression in breast cancer. Cancer Res 2002, 62:632-635.

8. Hu M, Peluffo G, Chen H, Gelman R, Schnitt S, Polyak K: Role of COX-2 in epithelial-stromal cell interactions and progression of ductal carcinoma in situ of the breast. Proc Natl Acad Sci U S A 2009, 106:3372-3377.

9. Laga AC, Zander DS, Cagle PT: Prognostic significance of cyclooxygenase 2 expression in 259 cases of non-small cell lung cancer. Arch Pathol Lab Med 2005, 129:1113-1117.

10. Sweeney CJ, Marshall MS, Barnard DS, Heilman DK, Billings SD, Cheng L, Marshall SJ, Yip-Schneider MT: Cyclo-oxygenase-2 expression in primary cancers of the lung and bladder compared to normal adjacent tissue. Cancer Detect Prev 2002, 26:238-244.

11. Ristimaki A, Nieminen O, Saukkonen K, Hotakainen K, Nordling S, Haglund C: Expression of cyclooxygenase-2 in human transitional cell carcinoma of the urinary bladder. Am J Pathol 2001, 158:849-853.

12. Wang D, Mann JR, Dubois RN: The role of prostaglandins and other eicosanoids in the gastrointestinal tract. Gastroenterology 2005, 128:1445-1461.

13. Wang D, Dubois RN: Eicosanoids and cancer. Nat Rev Cancer 2010, 10:181-193.

14. Wang $D$, Dubois RN: The role of COX-2 in intestinal inflammation and colorectal cancer. Oncogene 2010, 29:781-788

15. Sahin $I H$, Hassan MM, Garrett CR: Impact of non-steroidal anti-inflammatory drugs on gastrointestinal cancers: current state-of-the science. Cancer Lett 2013, 345:249-257.

16. Cheng J, Fan XM: Role of cyclooxygenase-2 in gastric cancer development and progression. World J Gastroenterol 2013, 19:7361-7368.

17. Dubois RN, Abramson SB, Crofford L, Gupta RA, Simon LS, Van De Putte LB, Lipsky PE: Cyclooxygenase in biology and disease. FASEB J 1998, 12:1063-1073.

18. Allaj V, Guo C, Nie D: Non-steroid anti-inflammatory drugs, prostaglandins, and cancer. Cell Biosci 2013, 3:8.

19. Juuti A, Louhimo J, Nordling S, Ristimaki A, Haglund C: Cyclooxygenase-2 expression correlates with poor prognosis in pancreatic cancer. J Clin Pathol 2006, 59:382-386.

20. Kokawa A, Kondo H, Gotoda T, Ono H, Saito D, Nakadaira S, Kosuge T, Yoshida S: Increased expression of cyclooxygenase-2 in human pancreatic neoplasms and potential for chemoprevention by cyclooxygenase inhibitors. Cancer 2001, 91:333-338.

21. Matsubayashi H, Infante JR, Winter J, Klein AP, Schulick R, Hruban R, Visvanathan K, Goggins M: Tumor COX-2 expression and prognosis of patients with resectable pancreatic cancer. Cancer Biol Ther 2007, 6:1569-1575.

22. Merati K, Said SM, Andea A, Sarkar F, Ben-Josef E, Mohammad R, Philip P, Shields AF, Vaitkevicius V, Grignon DJ, Adsay NV: Expression of inflammatory modulator COX-2 in pancreatic ductal adenocarcinoma and its relationship to pathologic and clinical parameters. Am J Clin Oncol 2001, 24:447-452

23. Molina MA, Sitja-Arnau M, Lemoine MG, Frazier ML, Sinicrope FA: Increased cyclooxygenase-2 expression in human pancreatic carcinomas and cell lines: growth inhibition by nonsteroidal anti-inflammatory drugs. Cancer Res 1999, 59:4356-4362.

24. Okami J, Yamamoto H, Fujiwara Y, Tsujie M, Kondo M, Noura S, Oshima S, Nagano H, Dono K, Umeshita K, Ishikawa O, Sakon M, Matsuura N, Nakamori $\mathrm{S}$, Monden M: Overexpression of cyclooxygenase-2 in carcinoma of the pancreas. Clin Cancer Res 1999, 5:2018-2024

25. Tucker ON, Dannenberg AJ, Yang EK, Zhang F, Teng L, Daly JM, Soslow RA, Masferrer JL, Woerner BM, Koki AT, Fahey TJ III: Cyclooxygenase-2 expression is up-regulated in human pancreatic cancer. Cancer Res 1999, 59:987-990
26. Yip-Schneider MT, Barnard DS, Billings SD, Cheng L, Heilman DK, Lin A, Marshall SJ, Crowell PL, Marshall MS, Sweeney CJ: Cyclooxygenase-2 expression in human pancreatic adenocarcinomas. Carcinogenesis 2000, 21:139-146.

27. Albazaz R, Verbeke CS, Rahman SH, McMahon MJ: Cyclooxygenase-2 expression associated with severity of PanIN lesions: a possible link between chronic pancreatitis and pancreatic cancer. Pancreatology 2005, 547:361-369.

28. Hermanova M, Trna J, Nenutil R, Dite P, Kala Z: Expression of COX-2 is associated with accumulation of p53 in pancreatic cancer: analysis of COX-2 and p53 expression in premalignant and malignant ductal pancreatic lesions. Eur J Gastroenterol Hepatol 2008, 20:732-739.

29. Maitra A, Ashfaq R, Gunn CR, Rahman A, Yeo CJ, Sohn TA, Cameron JL, Hruban RH, Wilentz RE: Cyclooxygenase 2 expression in pancreatic adenocarcinoma and pancreatic intraepithelial neoplasia: an immunohistochemical analysis with automated cellular imaging. Am J Clin Pathol 2002, 118:194-201.

30. Crowell PL, Schmidt CM, Yip-Schneider MT, Savage JJ, Hertzler DA, Cummings WO: Cyclooxygenase-2 expression in hamster and human pancreatic neoplasia. Neoplasia 2006, 8:437-445

31. Perrone G, Santini D, Zagami M, Vincenzi B, Verzi A, Morini S, Borzomati D, Coppola R, Antinori A, Magistrelli P, Tonini G, Rabitti C: COX-2 expression of ampullary carcinoma: correlation with different histotypes and clinicopathological parameters. Virchows Arch 2006, 449:334-340.

32. Santini D, Vincenzi B, Tonini G, Scarpa S, Vasaturo F, Malacrino C, Vecchio F, Borzomati D, Valeri S, Coppola R, Magistrelli P, Nuzzo G, Picciocchi A: Cyclooxygenase-2 overexpression is associated with a poor outcome in resected ampullary cancer patients. Clin Cancer Res 2005, 11:3784-3789.

33. Kim HJ, Sohn TS, Lee KT, Lee JK, Paik SW, Rhee JC: Expression of cyclooxygenase- 2 and its correlation with clinicopathologic factors of ampulla of vater cancer. J Korean Med Sci 2003, 18:218-224.

34. Kim HJ, Lee KT, Kim EK, Sohn TS, Heo JS, Choi SH, Choi DI, Lee JK, Paik SW, Rhee JC: Expression of cyclooxygenase-2 in cholangiocarcinoma: correlation with clinicopathological features and prognosis. J Gastroenterol Hepatol 2004, 19:582-588.

35. Westgaard A, Tafjord S, Farstad IN, Cvancarova M, Eide TJ, Mathisen O, Clausen OP, Gladhaug IP: Resectable adenocarcinomas in the pancreatic head: the retroperitoneal resection margin is an independent prognostic factor. BMC Cancer 2008, 8:5

36. Westgaard A, Schjolberg AR, Cvancarova M, Eide TJ, Clausen OP, Gladhaug IP: Differentiation markers in pancreatic head adenocarcinomas: MUC1 and MUC4 expression indicates poor prognosis in pancreatobiliary differentiated tumours. Histopathology 2009, 54:337-347.

37. Westgaard A, Tafjord S, Farstad IN, Cvancarova M, Eide TJ, Mathisen O, Clausen OP, Gladhaug IP: Pancreatobiliary versus intestinal histologic type of differentiation is an independent prognostic factor in resected periampullary adenocarcinoma. BMC Cancer 2008, 8:170.

38. Pomianowska E, Westgaard A, Mathisen O, Clausen OP, Gladhaug IP: Prognostic relevance of number and ratio of metastatic lymph nodes in resected pancreatic, ampullary, and distal bile duct carcinomas. Ann Surg Oncol 2013, 20:233-241.

39. Kong G, Kim EK, Kim WS, Lee KT, Lee YW, Lee JK, Paik SW, Rhee JC: Role of cyclooxygenase-2 and inducible nitric oxide synthase in pancreatic cancer. J Gastroenterol Hepatol 2002, 17:914-921.

40. Aprile G, Avellini C, Reni M, Mazzer M, Foltran L, Rossi D, Cereda S, laiza E, Fasola G, Piga A: Biglycan expression and clinical outcome in patients with pancreatic adenocarcinoma. Tumour Biol 2013, 34:131-137.

41. Hermanova M, Karasek P, Tomasek J, Lenz J, Jarkovsky J, Dite P: Comparative analysis of clinicopathological correlations of cyclooxygenase-2 expression in resectable pancreatic cancer. World J Gastroenterol 2010, 16:1879-1884.

42. Warner TD, Mitchell JA: Cyclooxygenases: new forms, new inhibitors, and lessons from the clinic. FASEB J 2004, 18:790-804.

43. Chang DK, Jamieson NB, Johns AL, Scarlett CJ, Pajic M, Chou A, Pinese M, Humphris JL, Jones MD, Toon C, Nagrial AM, Chantrill LA, Chin VT, Pinho AV, Rooman I, Cowley MJ, Wu J, Mead RS, Colvin EK, Samra JS, Corbo V, Bassi C, Falconi M, Lawlor RT, Crippa S, Sperandio N, Bersani S, Dickson EJ, Mohamed MA, Oien KA: Histomolecular phenotypes and outcome in adenocarcinoma of the ampulla of vater. J Clin Oncol 2013, 31:1348-1356. 
44. Overman MJ, Zhang J, Kopetz S, Davies M, Zhi-Qin J, Stemke-Hale K,

Rummele P, Pilarsky C, Grutzmann R, Hamilton S, Hwang R, Abbruzzese JL, Varadhachary G, Broom B, Wang H: Gene expression profiling of ampullary carcinomas classifies ampullary carcinomas into biliary-like and intestinal-like subtypes that are prognostic of outcome. PLOS ONE 2013, 8:e65144.

45. Eibl G, Bruemmer D, Okada Y, Duffy JP, Law RE, Reber HA, Hines OJ: PGE(2) is generated by specific COX-2 activity and increases VEGF production in COX-2-expressing human pancreatic cancer cells. Biochem Biophys Res Commun 2003, 306:887-897.

46. Colby JK, Klein RD, McArthur MJ, Conti CJ, Kiguchi K, Kawamoto T, Riggs PK, Pavone Al, Sawicki J, Fischer SM: Progressive metaplastic and dysplastic changes in mouse pancreas induced by cyclooxygenase-2 overexpression. Neoplasia 2008, 10:782-796.

47. Muller-Decker K, Furstenberger G, Annan N, Kucher D, Pohl-Arnold A, Steinbauer B, Esposito I, Chiblak S, Friess H, Schirmacher P, Berger I: Preinvasive duct-derived neoplasms in pancreas of keratin 5-promoter cyclooxygenase-2 transgenic mice. Gastroenterology 2006, 130:2165-2178.

48. Hill R, Li Y, Tran LM, Dry S, Calvopina JH, Garcia A, Kim C, Wang Y, Donahue TR, Herschman HR, Wu H: Cell intrinsic role of COX-2 in pancreatic cancer development. Mol Cancer Ther 2012, 11:2127-2137.

49. Omura N, Griffith M, Vincent A, Li A, Hong SM, Walter K, Borges M, Goggins M: Cyclooxygenase-deficient pancreatic cancer cells use exogenous sources of prostaglandins. Mo/ Cancer Res 2010, 8:821-832.

50. Walker RA: Quantification of immunohistochemistry-issues concerning methods, utility and semiquantitative assessment I. Histopathology 2006, 49:406-410

51. Koshiba T, Hosotani R, Miyamoto Y, Wada M, Lee JU, Fujimoto K, Tsuji S, Nakajima S, Doi R, Imamura M: Immunohistochemical analysis of cyclooxygenase-2 expression in pancreatic tumors. Int J Pancreatol 1999, 26:69-76.

doi:10.1186/1471-2407-14-458

Cite this article as: Pomianowska et al:: COX-2 overexpression in resected pancreatic head adenocarcinomas correlates with favourable prognosis. BMC Cancer 2014 14:458.

\section{Submit your next manuscript to BioMed Central and take full advantage of:}

- Convenient online submission

- Thorough peer review

- No space constraints or color figure charges

- Immediate publication on acceptance

- Inclusion in PubMed, CAS, Scopus and Google Scholar

- Research which is freely available for redistribution 